\title{
Reflexões sobre o papel das mulheres na economia solidária
}

\author{
Reflections on the role of women in the solidarity economy \\ Reflexiones sobre el papel de la mujer en la economía solidaria
}

\author{
Geisa Daise Gumiero Cleps ${ }^{1}$ \\ Lidiane Aparecida Marques ${ }^{2}$ \\ Andrea Costa van Herk Vasconcelos ${ }^{3}$
}

\begin{abstract}
RESUMO: A economia solidária, como forma de resistência ao sistema capitalista, tem sido uma alternativa importante de valorização das mulheres em situação de exclusão, discriminação e desemprego, pois há reconhecimento das especificidades femininas e masculinas em um mesmo espaço sem fazer distinção, com decisão coletiva, além de integrar o acesso à formação, compartilhar informações, experiências e saberes. Neste relato de experiência, o objetivo é refletir sobre a participação democrática das mulheres e suas relações de gênero na economia solidária, compreendendo sua atuação como possível estratégia de emancipação, geração de trabalho e renda, bem como de inclusão social. Para tal, aportou-se em conhecimentos teóricos e práticos, por meio de pesquisas sobre a economia solidária, visitas com narrativas, entrevistas semiestruturadas e individuais, realizadas em Empreendimentos de Economia Solidária (EES) em Uberlândia-MG, finalizando com uma Roda de Conversa, em maio/2019, na Universidade Federal de Uberlândia (UFU), com participantes que integram os EES e outros que buscaram conhecimento compartilhado. Percebeu-se que, apesar dos avanços da atuação da mulher nesses empreendimentos, significativos limites são evidenciados para a integração de ações e a efetividade dos resultados.
\end{abstract}

Palavras-chave: Mulheres. Economia solidária. Empreendimentos econômicos solidários.

Abstract: Solidary economy, while a form of resistance to capitalist system, has been an important alternative for valuing women in situations of exclusion, discrimination and unemployment, since there is recognition of female and male specificities in the same space without making a distinction, with collective decision, besides integrating access to training, sharing information, experiences and knowledge. In this experience report the objective is to reflect on the women democratic participation and their gender relations in the solidary economy, understanding their performance as a possible strategy for emancipation, job creation and income, as well as social inclusion. For this, it is guided by theoretical and practical knowledge, through research on solidary economy, visits with narratives, semistructured and individual interviews, carried out in Solidary Economy Enterprises (EES) in Uberlândia (MG), ending with a Conversation Circle, in May/2019, at the Federal University of Uberlândia (UFU), with participants who integrate EES and others who sought shared

\footnotetext{
${ }^{1}$ Doutora em Geografia pela Universidade Estadual Paulista Júlio de Mesquita Filho, Campus de Rio Claro, São Paulo, Brasil; com estágio pós-doutoral na Universidade Federal de Sergipe, Brasil; professora associada do Instituto de Geografia da Universidade Federal de Uberlândia, Minas Gerais, Brasil (gdgumiero@ufu.br).

2 Graduada em Geografia pela Universidade Federal de Uberlândia, Minas Gerais, Brasil (lidianeapda@hotmail.com).

3 Doutoranda em Geografia na Universidade Federal de Uberlândia, Minas Gerais, Brasil; professora da Faculdade de Gestão e Negócios da Universidade Federal de Uberlândia, Minas Gerais, Brasil (andreaherk@ufu.br).
} 
knowledge. Despite the advances made by women in these enterprises, significant limits are evidenced for actions integration and the effectiveness of results.

Keywords: Women. Solidarity economy. Solidary economic enterprises.

RESUMEN: La economía solidaria, como una forma de resistencia al sistema capitalista, ha sido una alternativa importante para valorar a las mujeres en situaciones de exclusión, discriminación y desempleo, ya que hay un reconocimiento de las especificidades femeninas y masculinas en el mismo espacio sin hacer una distinción, además de integrar el acceso a la capacitación, compartir información, decisiones, experiencias y conocimientos. En este informe de experiencia, el objetivo fue reflexionar sobre la participación democrática de las mujeres y sus relaciones de género en la economía solidaria, entendiendo su desempeño como una posible estrategia para la emancipación, la generación de empleo e ingresos, así como la inclusión social. Con este fin, buscamos conocimientos teóricos y prácticos en la investigación sobre la economía solidaria, visitas con narrativas y entrevistas semiestructuradas e individuales, realizadas en Empresas de Economía Solidaria (EES) en Uberlândia (MG), que finalizan con una Rueda de conversación, en mayo/2019, en la Universidad Federal de Uberlândia (UFU), con participantes de las EES y otros que buscaron conocimiento compartido. Se observó que, a pesar de los avances en el desempeño de las mujeres en estos emprendimientos, son evidentes y significativos los límites para la integración de acciones y la efectividad de los resultados.

Palabras clave: Mujeres. Economía solidaria. Empresas económicas solidarias.

\section{INTRODUÇÃO}

Este trabalho é resultado parcial do projeto de extensão Desenvolvimento Territorial, Economia Solidária e a Participação da Mulher nos Empreendimentos Econômicos Sociais (EES) de Uberlândia (MG), registrado sob o número 19680/2019.

Partiu-se da compreensão sobre a desvalorização das mulheres ao longo da história, considerando as possibilidades e as formas de ocupações exercidas nas esferas produtivas e reprodutivas. Historicamente, as mulheres são as principais responsáveis pelo trabalho doméstico e familiar, enquanto aos homens destina-se o papel predominante no trabalho produtivo e na política. $\mathrm{O}$ trabalho produtivo das mulheres ainda aparece mais como uma "ajuda" do que como parte efetiva integrante da renda familiar, mesmo quando se configuram como o único esteio da família (AZEVEDO et al., 2008). Um dos vieses do desequilíbrio entre gêneros (feminino e masculino) pode ser entendido por Kaloustian (2000), que se valeu da contemporaneidade do século XXI para refletir sobre a modificação dos arranjos familiares, nos quais muitas mulheres vêm se tornando chefes de famílias, tanto no meio urbano, quanto no rural. 
Observa-se que a economia capitalista se apropria do trabalho feminino, aprofundando a divisão sexual do trabalho com a segregação trabalhista, pois as mulheres, ao adquirirem emancipação parcial, passaram a conciliar habilidades e administração do tempo, aumentando a sobrecarga de trabalho devido à multiplicidade de tarefas (trabalhadora, esposa, dona de casa e mãe). De acordo com dados do IBGE (2019), as mulheres dedicam mais horas que os homens às tarefas domésticas e ao cuidado de pessoas, mesmo considerando situações de ocupações em atividades remuneradas, cumprindo 21,3 horas semanais, enquanto os homens 10,9 horas.

Entende-se que a economia solidária (ES), enquanto forma de resistência e sobrevivência ao sistema capitalista, é baseada no respeito, na igualdade, na solidariedade, na responsabilidade, na reciprocidade, na coletividade, no trabalho humano e na cooperação; e tem sido uma alternativa importante de valorização das mulheres em situação de exclusão, discriminação e desemprego. Assim, acredita-se haver na ES reconhecimento das especificidades femininas e masculinas em um mesmo espaço sem distinção, com decisão coletiva, integrando o acesso à formação, além do compartilhamento de informações, experiências e saberes.

Para Arruda (2006), a ES não deve ser reinventada somente por novas formas de trabalho, mas deve também integrar indivíduos que priorizam os valores humanos, dentre eles a participação da mulher nos Empreendimentos Econômicos Solidários (EES). O recorte dos empreendimentos com caráter solidário busca uma solução ou minimização para a desigualdade de gênero, uma vez que as organizações que compõem a emaranhada área do terceiro setor, principalmente as que geram trabalho e renda, assentam-se no conceito de ajuda mútua e sustentabilidade (NOGUEIRA, 2004), com possibilidades de maior autonomia, representatividade e participação das mulheres em grupos sociais, possibilitando uma (re) significação do trabalho (CARDOSO; TEODÓSIO, 2011).

As organizações solidárias surgem, neste contexto, como espaço aberto à participação das mulheres, pois, em geral, são voltadas para a produção de bens e prestação de serviços, cujas possibilidades são diversas, considerando o universo feminino. Por um lado, nessas iniciativas ilustra-se uma característica interessante das mulheres, apontando que elas primam pela organização coletiva como forma de potencializar a geração de trabalho e renda. Por outro lado, desenha-se um cenário de difícil atuação e até mesmo antagônico, o que, por sua natureza pode evidenciar uma zona de conflitos (GUÉRIN, 2005). 
Nesses empreendimentos, principalmente nas atividades manuais, as mulheres têm participação maciça e, no geral, as organizações são voltadas para a produção de bens e a prestação de serviços. Muito embora, como afirma Guérin (2005), algumas vezes essa participação é evidenciada não pela natureza do empreendimento, mas sim pela necessidade de atuação. Guerra e Toledo (2010) reforçam que existe o desenvolvimento de um conceito, pois muitas mulheres inseridas em organizações que geram trabalho e renda, lá o estão não por opção, mas, sim, por falta dela.

Assim, o objetivo deste relato de experiência é refletir sobre a participação das mulheres e suas relações de gênero na ES, compreendendo sua atuação como uma possível estratégia de emancipação, geração de trabalho e renda, bem como de inclusão social.

\section{METODOLOGIA}

Esse estudo possuiu abordagem qualitativa, baseado em conhecimentos teóricos decorrentes de levantamentos bibliográficos, de trabalhos acadêmicos (artigos, monografias, teses, dentre outros) referentes ao tema pesquisado, bem como de conhecimentos práticos por meio de pesquisa empírica sobre a ES em Minas Gerais, esta incluiu visitas em pesquisas de campo, narrativas, entrevistas semiestruturadas e individuais realizadas em EES em Uberlândia. Para complemento dos resultados, realizou-se uma Roda de Conversa, em maio/2019, como parte das atividades da V Jornada Universitária em Defesa da Reforma Agrária (JURA), na Universidade Federal de Uberlândia (UFU), com participantes de EES e outros que buscaram conhecimento compartilhado.

Para a apresentação desse relato, optamos por dividi-lo em três etapas, a saber:

(1) Descrição dos EES a partir da realização de uma pesquisa de iniciação científica e projetos de pesquisa financiados por órgãos de fomento (CNPq e FAPEMIG), incluindo a coleta de dados em sites disponibilizados na internet, como o site do extinto Ministério do Trabalho e Emprego (MTE), que integra a página do Cadastro Nacional de Empreendimentos Econômicos Solidários e Comércio Justo (CADSOL). Os dados obtidos passaram por análises e elaboração de tabelas com esboço no software Excel, contendo a identificação das mesorregiões, das microrregiões, dos municípios, do número de EES e dos associados e associadas integrantes dos EES. 
(2) Apresentação de um caso (aqui denominado como Ilha das Flores - nome fictício) sobre as relações de gênero que emergem de mulheres gestoras na economia solidária, resultado de pesquisa de mestrado (VALADÃO JÚNIOR; VAN HERK; MEDEIROS, 2014), oriunda da base de dados ligada à Secretaria Nacional de Economia Solidária (SENAES) e utilizada pelo Grupo de Pesquisa em Organizações do Terceiro Setor da Universidade Federal de Uberlândia, no período 2010-2011.

Ilha das Flores: Um dos objetivos específicos da pesquisa foi identificar as três categorias propostas por Medeiros (2008) - cúmplice, resistente, confrontador - e/ou descobrir outra(s) categoria(s) presente(s) nas relações de gênero em EES. O empreendimento participante deste relato foi concebido por meio de iniciativas da sociedade civil, em parceria com a Igreja Católica, cuja ideia inicial era transformar uma realidade social crítica.

(3) Apresentação dos resultados oriundos da Roda de Conversa na V JURA. No evento, foi apresentado o contexto atual da participação das mulheres em EES, relacionando-o às realizações, dificuldades e limites existentes em virtude da situação econômica, política e cultural enfrentada pelas mulheres na economia solidária. Partiu-se desses apontamentos e dos resultados apresentados na primeira e segunda etapa dessa metodologia, com o propósito de suscitar questionamentos e reflexões dialógicas sobre a temática, a fim de obter o máximo de contribuições possíveis. A Roda de Conversa teve participação de dez pessoas, moderadores e secretária para estimular as reflexões e discussões dos participantes. As contribuições foram anotadas para transcrição e finalização do texto como relato de experiência.

\section{RESULTADOS E DISCUSSÃO}

Como apontado, na ES, os EES são as diversas iniciativas econômicas provenientes de decisões dos próprios trabalhadores no meio rural ou/e urbano e envolvem basicamente atividades de produção, comercialização e serviços, nas quais ocorre fabricação e/ou vendas de produtos, trocas, prestação de serviços, finanças solidárias e consumo.

Uma das características primordiais de identificação dos empreendimentos econômicos solidários é "ser uma organização coletiva e democrática, singular ou complexa, cujos participantes ou sócios são trabalhadores do meio urbano ou rural” (BRASIL, 2015, p. 8). Nesse contexto, o CADSOL foi instituído pela Portaria $n^{\circ} 1780$, de 19 de novembro de 2014, do Ministério do Trabalho e Emprego, sendo atualizado periodicamente em relação ao 
número de empreendimentos registrados nos estados brasileiros, incluindo Minas Gerais, estado trabalhado nessa pesquisa.

A partir dos dados levantados pelo CADSOL, no ano de 2019, foram constatados 2.556 empreendimentos em Minas Gerais, sendo registrados 72.122 associados, 38.727 mulheres e 33.395 homens. Na mesorregião do Triângulo Mineiro/Alto Paranaíba registrou-se 7.158 associados, 3.307 mulheres e 3851 homens. Em Uberlândia, onde as pesquisas de campo foram realizadas, identificou-se 1.295 associados, 759 mulheres e 536 homens. De acordo com os dados levantados, foi possível observar o predomínio de mulheres associadas no estado mineiro (38.727), assim como em Uberlândia (759 mulheres). Percebe-se, a partir desses números, o interesse e o envolvimento feminino na conquista de espaço solidário e equitativo nas diversas iniciativas desenvolvidas na economia solidária.

Podemos destacar as atividades de produção e comercialização artesanal de doces, geleias, bolos, tapetes, crochê, artigos de viagens e de decoração (incluindo a matéria-prima na reutilização de materiais recicláveis), bijuterias, confecção de peças do vestuário, roupas íntimas e de bordados, além da fabricação de alimentos, e na prestação de serviços em lavanderias e alimentação. Utilizou-se, como critério de exemplificação, uma Lavanderia Comunitária para registrar a presença das mulheres nos empreendimentos em Minas Gerais.

Essa Lavanderia Comunitária surgiu como uma fonte complementar de renda para as mulheres e por meio da divulgação do empreendimento houve a inclusão de novas pessoas. A organização do trabalho acontece pela demanda dos clientes (clientela fixa e variada). $\mathrm{O}$ serviço é executado por lavadeiras e passadeiras que necessitam de conhecimento, atenção e adaptação para atingir os resultados previstos coletivamente pelo grupo.

Na lavanderia, cada passadeira conta com uma pessoa que lava as roupas com a utilização de materiais próprios. As roupas são estendidas e separadas após passadas, conforme a quantidade e os modelos deixados pelos clientes. Por isso, o desafio identificado pelas associadas está na organização (aprender a separar), na adaptação e memorização do trabalho. Nesse contexto, percebe-se que as mulheres participantes dos EES, como apontado por Guérin (2005) e Guerra e Toledo (2010), lá estão muitas vezes não por opção, e sim, por falta dela, necessitando de capacitação e autonomia, questões que possibilitem sua efetiva emancipação e (re) significação do trabalho (CARDOSO; TEODÓSIO, 2011). 
Para o entendimento dos desafios e dificuldades enfrentados pelas mulheres nos EES frente ao discurso dominante (ora do homem, ora até de outra mulher), optou-se por apresentá-los a partir das categorias expostas por Medeiros (2008), quais sejam, cumplicidade, resistência e confronto, características pessoais elencadas a partir do trabalho feminino nas organizações de economia solidária. Para tanto, buscou-se por apresentar um caso, um EES aqui denominado como Ilha das Flores.

\section{Ilha das Flores}

A partir da pesquisa, análise documental e entrevistas - a categoria "resistência" foi a primeira a se fazer presente no trabalho feminino no Ilha das Flores, caracterizada por padrões resistentes aos discursos dominantes, verificada em vários relatos em que o "eu" impera sobre o "nós" (GUÉRIN, 2005). De forma explícita, os sujeitos escutam outros membros do EES, mas há atitudes implícitas atribuídas a comportamentos que denotam certa resistência aos discursos dominantes (figura masculina), principalmente quando o sujeito se apresenta "de fora do empreendimento".

O "confronto" representa situações em que as mulheres não aceitam os discursos dominantes e, seja de forma verbal, seja na forma de gestos (olhares desviados, dentre outras representações não verbais), rejeitam as situações nas quais o discurso dominante impera. Verificou-se o confronto no Ilha das Flores de forma mais implícita do que explícita, explicado por características como indignação, rebeldia, ou mesmo raiva, originando comportamentos agressivos por ideias e conceitos pré-concebidos. Nessas situações, não importa se as relações são representadas pelo masculino com o feminino ou pelo feminino com outro feminino, pois, quando da inconformidade ao status quo, os sujeitos mostram seu posicionamento.

A categoria "cúmplice" compreende as situações em que este ou aquele sujeito "aceita" e até reforça um status quo, representando conformidade ou subordinação da mulher perante o discurso dominante (MEDEIROS, 2008). No Ilha das Flores observou-se que, quando a relação de gênero se refere ao masculino/feminino, as mulheres parecem usar de um estratagema a fim de tomarem suas próprias decisões, ouvindo a exposição dos homens, mas seguindo suas próprias convicções, demonstrando assim uma "pseudo" cumplicidade. O caráter estratégico de adaptar-se às situações, unindo-se ao "tipo ideal" das mulheres no 
ambiente de trabalho, confere potencialidades às nuances de intuição, emoção, cooperação e espontaneidade, próprias das mulheres, aqui interpretados a partir de uma característica "camaleônica" - categorias cumplicidade e confronto, juntas - das mulheres (CALDAS; TONELLI, 2000; SHEPPARD, 1989).

A partir dessas percepções e contexto atual econômico, político e cultural que permeia o universo das mulheres na economia solidária, procurou-se estabelecer discussões e reflexões na Roda de Conversa da V JURA com participantes de EES e outros que buscaram compartilhar conhecimentos. Os resultados estão descritos logo a seguir.

\section{Roda de conversa}

Primeiramente, cumpre-se esclarecer que o recorte escolhido pelos participantes da Roda de Conversa na V JURA, dentre os vários segmentos da ES, foi o da Agroecologia, ou seja, os EES que propiciam geração de trabalho e renda, que integram técnica e prática e compõem a formação do Centro de Incubação de Empreendimentos Econômicos Solidários (CIEPS) da UFU. Estavam presentes também, a critério de buscar conhecimento, mulheres artesãs independentes.

Percebeu-se, a partir da fala dos participantes, que tanto a produção quanto o consumo de alimentos orgânicos e agroecológicos vêm compondo a agenda de discussões em vários âmbitos e, para o pequeno agricultor familiar e camponês é uma oportunidade de (re) significar relações e onde há a valorização do trabalho da mulher, principalmente numa filosofia de envolver toda a família. "Nessas condições, a importância da mulher está para além do trabalho do homem, evidenciada, por exemplo, na soberania alimentar. É ela que cuida, com muita atenção, dos quintais agroecológicos no campo" (Participante, 2019). Ainda, "se não valorizar a mulher, por exemplo, não é agroecologia”. (Participante, 2019).

Nesse contexto da produção de alimentos agroecológicos, verificou-se que o trabalho da mulher é elemento essencial de geração de renda e de sobrevivência, pois numa lógica de cuidado e de envolvimento da família, a dinâmica da produção, da comercialização e do consumo não necessita de atravessadores. Em outras palavras, na economia solidária agroecológica camponesa quem produz é quem vende por meio da autogestão, onde há gestão compartilhada e democrática com autonomia de todos os trabalhadores, bem como decisões e atividades realizadas em conjunto e, assim, “o esforço é recompensado" (Participante, 2019). 
Nessa reflexão, percebeu-se a preocupação dos sujeitos atuantes no segmento da agroecologia em relação ao bem-estar dos consumidores de maneira geral, ou seja, pensar e atuar numa produção equilibrada estimulando e propagando uma filosofia de sustentabilidade.

Percebeu-se também que apesar das mulheres participantes dos EES se virem como sujeitos essenciais nas atividades da ES, limites como acesso a políticas públicas de reconhecimento e valorização da mulher foram apontados pela Roda de Conversa e que ficaram evidenciados como dificuldades. Verificou-se, contudo, que os EES são iniciativas fundamentais para a expansão e o fomento da ES, pois com o coletivo há mais oportunidades de geração de trabalho e renda, em especial para as mulheres que ainda atuam de forma independente.

Nesse sentido, ficou registrada a importância de associar-se a um EES. A partir do coletivo é possível estimular e participar de fóruns, reuniões de apoio e troca de experiências. Capacitando-se e participando, é possível que as mulheres da economia solidária tenham acesso a práticas de administração, como produção, comercialização e gestão dos EES; a formas de buscar recursos financeiros a partir da articulação de agentes; clubes de trocas com o uso das moedas sociais, como forma de ajuda mútua de se organizar, sem explorar e ser explorado, dentre outros. "Através dessas organizações, é possível manter a solidariedade, favorecendo a identidade e a valorização do trabalho da mulher" (Participante, 2019).

\section{CONSIDERAÇÕES FINAIS}

A ES tem se mostrado uma alternativa importante e favorável para a valorização, a emancipação e a agregação das práticas experientes e tradicionais das mulheres que criam e recriam a partir de suas habilidades profissionais e culturais.

Neste estudo, observou-se que a participação das mulheres tem sido predominante e diversificada nas formas de organizações solidárias, incluindo atividades de produção e comercialização de alimentos, artesanatos, vestuários e serviços.

A ideia de solidariedade e coletividade, em contraposição ao individualismo, é comum em todas as abordagens que referenciam a presença feminina nos EES. Todavia, apesar dos avanços da atuação da mulher nesses empreendimentos, significativos limites ficaram evidenciados. Ainda é necessário maior envolvimento das pessoas, divulgação e reconhecimento social e político, através de assistências frequentes, incentivos, e recursos 
financeiros do poder público na formalização e conquista de espaço físico, que nem sempre é suficiente para comercializar os produtos da economia solidária; dentre outras questões que estimulam a integração de ações e a efetividade dos resultados.

Concomitantemente ao crescimento da atuação feminina em esferas fora do ambiente doméstico, os EES podem contribuir sobremaneira para atividades em âmbito coletivo. Dois fatores são considerados mais evidentes: (1) nos espaços da economia solidária é possível conciliar responsabilidades domésticas, como o cuidado com a família e a conquista de independência financeira; (2) os espaços coletivos evidenciam características próprias do gênero feminino (união, sensibilidade, cooperação, intuição).

A partir do exposto, como pontos importantes de discussões futuras, sugere-se a abordagem de questões que permeiem acesso à formação, ao compartilhamento de informações, saberes e experiências que evidenciem a atuação e emancipação das mulheres em empreendimentos da economia solidária.

\section{REFERÊNCIAS}

ARRUDA, M. Tornar real o possível: a formação do ser humano integral, economia solidária, desenvolvimento e o futuro do trabalho. Petrópolis, RJ: Vozes, 2006.

AZEVEDO, S. R. S. et al. Mulheres na construção de ações empreendedoras na zona rural de João Pessoa desenvolvida na Região do Baixo Gramame, João Pessoa, Paraíba. In: FAZENDO GÊNERO: CORPO, VIOLÊNCIA E PODER, 8. , 2008, Florianópolis. Anais [...]. Florianópolis, 2008.

BRASIL. Ministério do Trabalho. Cadastro Nacional de Empreendimentos Econômicos Solidários e Comércio Justo - CADSOL. Economia solidária. Disponível em: http://trabalho.gov.br/trabalhador-economia-solidaria/cadsol. Acesso em: 2 jan. 2020.

CATTANI, A. D. (org.). A outra economia. Porto Alegre: Veraz Editores, 2003.

GUÉRIN, I. As mulheres e a economia solidária. São Paulo: Edições Loyola, 2005.

GUERRA, A. C.; TOLEDO, D. A. C. Economia solidária e relações de gênero: analisando uma nova relação de trabalho. In: EnANPAD, 34., 2010. Anais [...]. Rio de Janeiro, 2010.

IBGE. Agência de notícias do IBGE. Disponível em: https://agenciadenoticias.ibge.gov.br/?fbclid=IwAR3b8OlLiBOHzbW_0fzQJCfrH5PMhN_h XgVvBk9GTXLecluroEVpTX42LPU. Acesso em: 26 jan. 2020.

KALOUSTIAN, S. M. Família brasileira a base de tudo. 4. ed. São Paulo: Cortez; Brasília, UNICEF, 2000. 
MEDEIROS, C. R. de O. Mulheres no Terceiro Setor: "mirem-se... no exemplo... daquelas mulheres...de Atenas...”. 2008. Dissertação (Mestrado em Administração) - Faculdade de Gestão de Negócios, Universidade Federal de Uberlândia, Uberlândia, 2008.

MUNDIM, F. L. C.; TEODÓSIO, A. S. S. Relações de gênero nas dinâmicas associativas solidárias: um estudo de caso no Assentamento Rural Pastorinhas. In: ENCONTRO NACIONAL DE PESQUISADORES EM GESTÃO - ENAPEGS, 5., 2011, Florianópolis. Anais [...]. Florianópolis, 2008.

NOGUEIRA, C. M. A feminização do mundo do trabalho. São Paulo: Autores Associados, 2004.

SHEPPARD, D. L. Organizations, power and sexuality: the image and self-image of women managers. In: HEARN, J. et al. (ed.). The sexuality of organization, London: Sage, 1989. p. 139-157.

VALADÃO JÚNIOR, V. M.; VAN HERK, A. C.; MEDEIROS, C. R. de O. Gênero e economia solidária: um olhar sobre a participação e atuação das mulheres nas organizações do terceiro setor em Uberlândia/MG. Gestão \& Planejamento, Salvador, v. 15, n. 2, p. 321-340, maio/ago. 2014. 